\title{
RESOURCE ALLOCATION IMPROVEMENT IN THE TASKS OF AIRPORT GROUND HANDLING OPERATIONS
}

\author{
Kristina MARINTSEVA ${ }^{1}$, Gennadiy YUN ${ }^{2}$, Sviatoslav KACHUR ${ }^{3}$ \\ ${ }^{1,2}$ Air Transportation Management Department, National Aviation University, Kiev, Ukraine \\ ${ }^{3}$ KYIV Ramp Manager, INTERAVIA LLC, Kiev, Ukraine \\ E-mail: kristin22@ua.fm (corresponding author)
}

Received 06 October 2014; accepted 20 January 2015

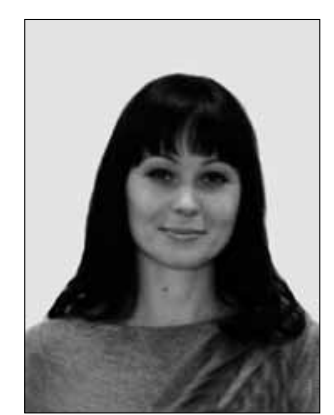

Kristina MARINTSEVA

Education: National Aviation University, Kiev, Ukraine, 2000.

Affiliations and functions: doctoral candidate, associate professor of Air Transportation

Management Department.

Research interests: operation and modelling of technological processes in air transport system.

Publications: author of more than 30 publications.

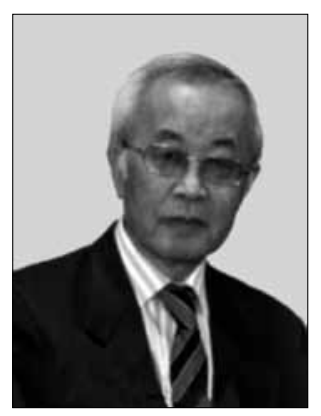

\section{Gennady YUN, Prof.}

Education: Kharkov Aviation University, Kharkov, Ukraine, 1962.

Affiliations and functions: doctor of engineering science, professor, head of Air Transportation Management Department.

Research interests: application of mathematical modelling for problem solving in air transportation systems and process optimization.

Publications: author of more than 130 publications.

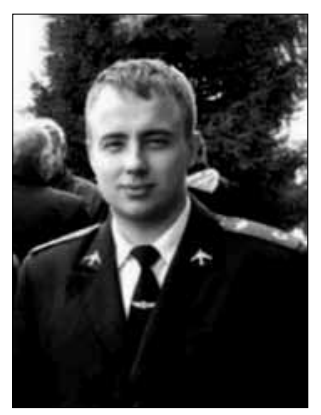

\section{Sviatoslav KACHUR}

Education: National Aviation University, Kiev, Ukraine, 2009.

Affiliations and functions: KYIV Ramp Manager.

Research interests: mathematical modelling application for problem solving in airport ground handling operations.

Publications: author of 3 publications.

Abstract. It is a global trend for the airport ground handling market to become liberalised. Fiercer competition lead to the necessity to improve efficiency and minimise costs. A mathematical model of optimal resource allocation by aircraft ground handling company using duality theory has been suggested. The numerical results for the solution of the task under the question which were obtained with the relevant software package, proved validity of the specified theoretical preconditions and allowed to improve the work schedule of the experimental aircraft ground handling company in accordance with a specified efficiency criterion.

Keywords: dual prices, air handling, service, resource, airport, aircraft. 


\section{Problem statement}

The airports have traditionally been viewed as the infrastructure providers for the airlines, but today the scholars consider the problem of services provision to the airlines from the point of view of the whole air transport system. The traffic flow structure has eventually changed that competition exists not only between separate airlines but includes their main airports.

One of the major aims of airports and airlines is to provide quality services which largely depend on their punctuality and safety (Gališanskis 2004). It is noted by S. Albers et al. (2005) that competition of international airlines is gradually boiled down to uniformity in the context of selling and provision of services in the air. Further on competition will be rather considered with regard to the services on the ground. In this case, the forms of interaction between the airports and airlines gain utmost importance.

The airport's functions and the services provided can be classified, distributed among the regional branches, divisions (subdivisions) using various ways and combinations.

Usually, the main function of the airport is to provide aviation and non-aviation related services to the users: airlines, passengers, consignors, consignees, etc. Some companies are provided with ground handling from the airports while in other cases such services are provided by the airlines or dedicated agencies or aircraft ground handling companies (AGHCs). Aircraft ground handling is a common term used to describe tasks concerning the aircraft's (AC) arrival or departure and which are performed while it is on the ground.

It is a global trend that the airport ground handling market becomes liberalised. On the territory of the European Union the airport ground handling market liberalisation was specified in the Directive 96/67/EC that triggered an increase of AGHCs by more than $80 \%$ and subsequent competition among them observed in between 1996 and 2007 (Airport... 2009). Fiercer competition led to the necessity to improve efficiency and minimise costs.

In recent years development of low cost carriers (LCC) defined the new issues with respect to aircraft ground handling. As opposed to the traditional airlines the LLCs can minimise turnaround time and number of operations to provide ground handling in order to minimise costs. This places considerable limitations upon AGHC's operating activities and increases the risk of regularity breakdown should any delays occur.

\section{Analysis of recent research and publications}

Efficient allocation of internal resources of an aircraft ground handling operator is one of the key factors for the civil aviation airports to operate. The task gains a particular significance for major AGHC with a large number of divisions which also have various technological ways to process passengers, cargo and AC and which are in charge of resources consumption (Clausen 2011).

Resource allocation should be carried out with consideration for production capabilities and needs of all AGHC divisions which handle the specified airports. The well-developed system of internal prices of resources, which functions within the given system, may serve to this purpose. The Soviet and foreign academic literature (Kantorovich 1959; Yudin, Holstein 2012; Lasdon 2002) a great deal of attention has paid to duality theory and dual estimates in particular. However, the issues of dual estimates applied use have been covered scarcely (excluding few publications, for example, S. Gdalevich (1974); G. N. Yun, K. V. Marintseva (2013).

\section{The results of the investigation}

\subsection{Input data}

Usually airport ground operations are carried out in airside and landside areas. Hence, two subdivisions can be introduced for ground handling in the AGHC's structure: those related to aircraft ground handling and terminal handling. The procedures for performing aircraft ground handling technological operations are specified in recommendations for each aircraft type in the Aircraft Handling Manual.

Figure 1 provides an example of the typical technology for handling aircraft and illustrates the types of activity. Some of them cannot be performed on a simultaneous basis. For instance, aircraft may be fuelled with passengers on-board, embarking or disembarking only under certain conditions (IATA 2014). Therefore, in "Kyiv" airport fuelling is usually not performed while passengers are boarding or disembarking. Other types of activity, such as watering, can be performed irrespective of other procedures.

For solving the linear issues of AGHC's work optimisation, internal prices can be built on the basis of dual estimates. The idea of using dual estimates for efficient allocation of scarce resources between AGHC divisions rests on the assumption that an original indicative solution of resource allocation has been drawn on the basis of past experience or some other considerations. This naturally raises the question of the possibility to improve it. To provide an answer one needs estimates pointing at the optimality or possibility of an original allocation solution. Dual estimates which have been obtained as a result of solving local tasks of optimisation of each subdivision's activities, taking into consideration the original resource allocation between them, can be adopted as such estimates. 
If the estimates for a certain resource differ in at least two divisions, then it is appropriate to reallocate this resource between them. For this purpose the value for the objective function of the division from which a part of the resource is being withdrawn can be somewhat reduced and increased for the one that this resource is being transferred to, while the cumulative effect would be stronger. To solve the problem of the quantity of the resource being reallocated, particular models of tasks for these two divisions should be joined into a single model with a common target function and common limitations with respect to the homogeneous resources being reallocated. The solution for the combined task will provide the best reallocation strategies of scarce resources between the divisions involved. Hence, all estimates for the same resources for these divisions will become equal. Afterwards, the joint model gets separated into two original type models again. The right parts of the limitations change simultaneously, in accordance with the obtained resource reallocation, etc. The process continues until the dual estimates become equal for the same resources in all divisions.

Now, let us consider an AGHC including a number of divisions, each rendering some type of service, and the centre providing $m$ types of resources to the divisions.

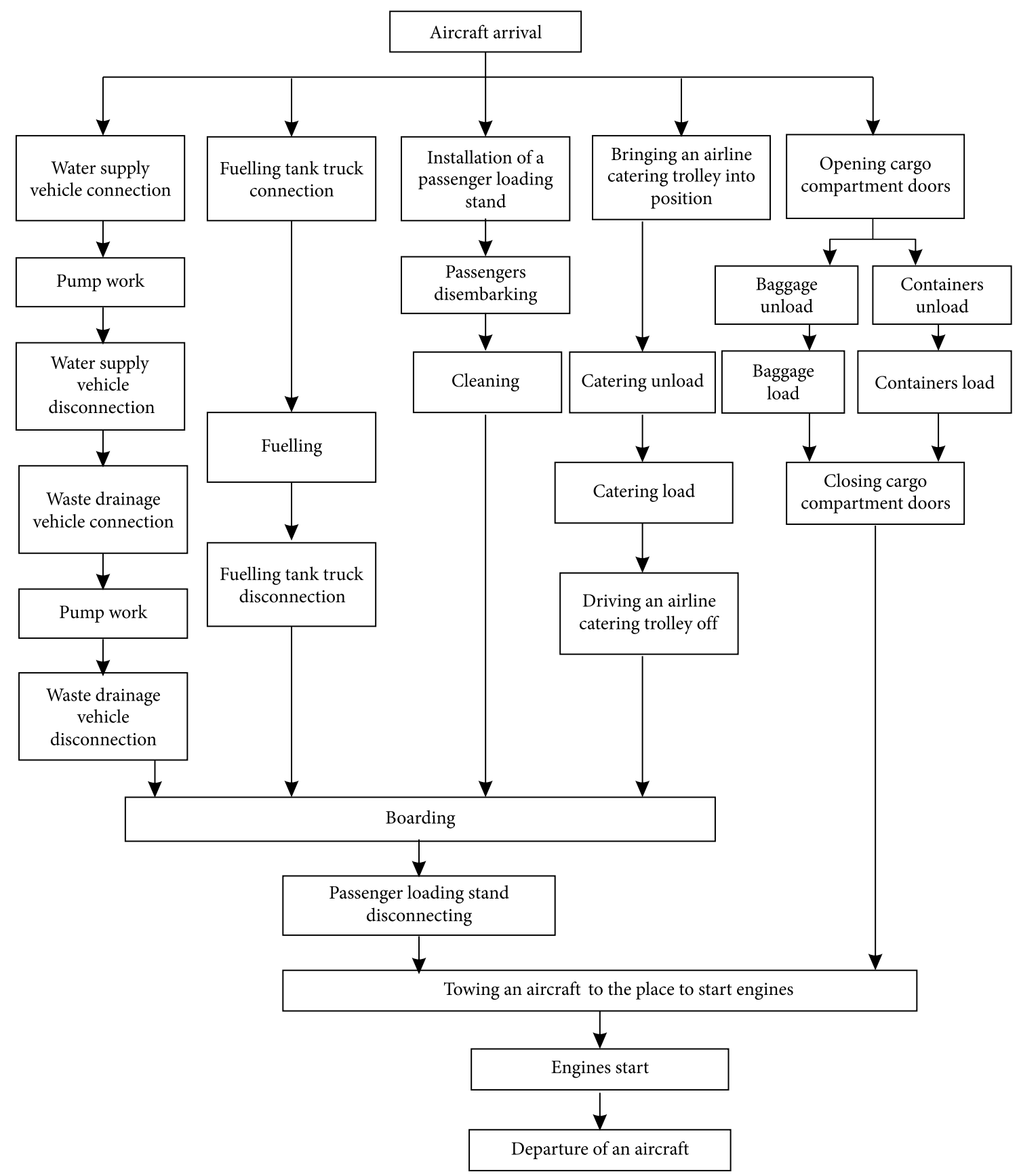

Fig. 1. Model sequence of ground handling for a turnaround flight (based on S. S. Vicente (2010)) 
To simplify further experimental calculations the set of services provided by each division will be considered as one type of service.

Let us introduce the following denotations:

$i$ - resource type index, $i=\overline{1, m}$;

$j$-AGHC division index, $j=\overline{1, n}$;

$a_{i j}$-resource quantity;

$\underline{X}_{j}$ and $\bar{X}_{j}$ - the lower and upper margins of an AGHC division's services volume;

Table 1. Input data for the experimental calculation (all data are privided into one calendar month)

\begin{tabular}{cccc}
\hline & \multicolumn{2}{c}{$i$} \\
\cline { 2 - 4 }$j$ & Name & $\begin{array}{l}\text { Funds, conv. } \\
\text { monetary units }\end{array}$ & $\begin{array}{l}\text { Personnel work- } \\
\text { ing time fund, h }\end{array}$ \\
\hline 1 & $\begin{array}{l}\text { Terminal } \\
\text { handling division }\end{array}$ & 70000 & 3000 \\
\hline 2 & $\begin{array}{l}\text { Aircraft ground } \\
\text { handling division }\end{array}$ & 215000 & 13000 \\
\hline
\end{tabular}

Table 2. Characteristics of ground handling technologies

\begin{tabular}{|c|c|c|}
\hline $\begin{array}{l}\text { Technology } \\
\text { variant }\end{array}$ & I & II \\
\hline $\begin{array}{l}\text { Airline } \\
\text { business } \\
\text { model }\end{array}$ & Traditional & Low cost \\
\hline $\begin{array}{l}\text { Amount of } \\
\text { passengers }\end{array}$ & $\begin{array}{l}\text { Including several } \\
\text { service classes (F, C, Y) }\end{array}$ & $\begin{array}{l}\text { Max. aircraft } \\
\text { passenger capacity }\end{array}$ \\
\hline $\begin{array}{l}\text { Check in } \\
\text { ( } 2 \text { hours prior } \\
\text { to departure) }\end{array}$ & $\begin{array}{l}\text { Provides for additional } \\
\text { resources to execute } \\
\text { transfer and a conside- } \\
\text { rable amount of } \\
\text { baggage }\end{array}$ & $\begin{array}{l}\text { Maximal } \\
\text { utilisation of } \\
\text { self-check-in } \\
\text { technology }\end{array}$ \\
\hline Catering & $\begin{array}{l}2 \text { vehicles to service a } \\
\text { galley }\end{array}$ & $\begin{array}{l}1 \text { vehicles to } \\
\text { service a galley }\end{array}$ \\
\hline $\begin{array}{l}\text { Filling with } \\
\text { potable water }\end{array}$ & \multicolumn{2}{|c|}{2001 (100\% refilling) } \\
\hline $\begin{array}{l}\text { Wastewater } \\
\text { disposal }\end{array}$ & \multicolumn{2}{|c|}{2001} \\
\hline $\begin{array}{l}\text { Aircraft } \\
\text { parking place }\end{array}$ & terminal & apron \\
\hline $\begin{array}{l}\text { Cargo (type } \\
\text { and quantity) }\end{array}$ & $4 \mathrm{ULD}$ & $\begin{array}{l}100 \text { baggage } \\
\text { places } \\
\text { (non-container } \\
\text { cargo) }\end{array}$ \\
\hline $\begin{array}{l}\text { Ground power } \\
\text { supply }\end{array}$ & air bridge & $\begin{array}{l}\text { Ground power } \\
\text { supply unit }\end{array}$ \\
\hline Cleaning & \multicolumn{2}{|l|}{ yes } \\
\hline Towing & $\begin{array}{l}\text { towbarless towing } \\
\text { tractor }\end{array}$ & $\begin{array}{l}\text { no (uncovered } \\
\text { apron) }\end{array}$ \\
\hline $\begin{array}{l}\text { Mean aircraft } \\
\text { turnaround } \\
\text { time }\end{array}$ & 27 minutes & 19 minutes \\
\hline
\end{tabular}

$T_{j}$ - quantity of technological ways to provide a service by AGHC division;

$p_{i j}^{t}$ - consumption of $i$ resource per unit of $j$ service, provided through $t$ technology;

$x_{j t}$ - the volume of $j$ service, provided through $t$ technology (target values), depending on source data availability these can be physical quantities or monetary values.

A set of some input data for the experimental calculation was completed on the basis of the work of some AGHCs in the Ukrainian airports (Table 1).

In our calculations we assume that ground handling technology depends on the airline business model (Table 2) and, requires consequently different amount of resources at certain stages (Fig. 1). AGHC operates mainly short- and medium-haul flights (up to $5000 \mathrm{~km}$ ), and the number of passengers ranges from 100 to 150 persons. The maximal aircraft take-off weight reaches 70 tonnes. The mean time of aircraft turnaround was got according typical turnaround Gantt chart for Boing 737 and Airbus 320 and appropriate observations in "Kyiv" airport. The using of a Unit Load Device (ULD) depends on the airline's management (Vicente 2010). ULD is more expensive because of the special equipment necessary for loading and must be previously packed. Therefore loading bags by handling staff is more typically in case of LCC ground technology model. For the scope of services assume the number of flights served for a month, while $\underline{X}_{j}=30$, and $\bar{X}_{j}=6000$. The AGHC's average profit per flight for provision of services at the air terminal for the traditional business model carrier amounts to 148 conv. monetary units, for low cost one it does to 112 conv. monetary units; for the aircraft ground handling this value amounts to 450 and 380 conv. monetary units, respectively. Assume maximum value of profit as an optimality criterion for each division and AGHC on the whole.

\subsection{Algorithm to solve the task}

At the first stage of solution let us allocate the stock vector $\overrightarrow{a_{i}}$ between the AGHC divisions in an arbitrary way (e.g. on the basis of an expert's experience). Let the first division be allocated $a_{i 1}$ units of $i$ resource, $i=\overline{1, m}$, and the second one be allocated $a_{i 2}$ and so on. In Table 3 observed results are presented, which based on financial and working time cost estimating per flight. For example, using the characteristics of ground handling technologies it is possible to calculate the expected turnaround prime cost. The personnel working time fund expenditures per flight were obtained by using the information about staff number necessary and time for fixed handling operations according with standard technical process.

Considering this allocation for each division let us compile a task to determine the optimal solution for 
service rendering. Thus, for $j$ division this task has the form as follows: to determine a solution $\left\{x_{j t}\right\}$, which allows achieving objective function maximum

$$
P_{j}=\sum_{t=1}^{T_{j}} c_{j t} x_{j t}
$$

subject to the following sets of constraints:

$$
\begin{aligned}
& x_{j t} \geq 0 ; \\
& \sum_{t=1}^{T_{j}} p_{i j}^{t} \quad x_{j t} \leq a_{i j} ; \\
& \bar{X}_{j} \geq \sum_{t=1}^{T_{j}} x_{j t} \geq \underline{X}_{j},
\end{aligned}
$$

where $c_{j t}$ is profit obtained by $j$ division of AGHC for having provided a single service using $t$ technology.

As a result of solving problems of (1)-(4) type for each division $j \in\{1, \ldots, n\}$, beside optimal solution $\left\{x_{j t}\right\}$ (for instance, $x_{11}=166$ is the optimal number of flights serviced by the terminal handling division through traditional technology model), we'll obtain the dual estimates vector $\left\{u_{i j}^{0}\right\}$, relevant to the constraints (3), and also the value of objective function $P_{j}^{0}$ (Table 4 ).

Let us compare dual estimates of the same name resources, obtained for different divisions. As it can be seen in table 4 they differ from each other considerably. This case may occur under non-optimal allocation of the given resources between the divisions. Indeed, if, for example, $U_{12}^{\circ}=17.5$, and $U_{22}^{\circ}=0$, then adding a unit of the 2 nd type of resource to the 1st division would result in 17.5 units of additional profit, but withdrawal of the unit of the same type resource from the 2nd division would bring zero reduction to profit. Therefore it makes sense to withdraw a certain amount of this resource from the 2nd division and transfer it to the 1st one.

Formally, let us do the following. After solving the tasks of (1)-(4) type we select two divisions $j_{1}$ and $j_{2}$ for which the difference of dual estimates by a certain resource $i_{1}$ is maximal, i.e. for which it:

$$
\begin{array}{ll} 
& \max \\
U_{i_{1 / 1}}^{\circ}-U_{i_{2 / 2}}^{\circ} & i \max \left[\left(U_{i j^{\prime}}^{\circ}\right]-U_{i j^{\prime \prime}}^{\circ}\right) . \\
& 1 \leq j^{\prime} \leq n ; 1 \leq j^{\prime \prime} \leq n
\end{array}
$$

For the divisions $j_{1}$ and $j_{2}$ a "local tasks" is formed to optimally reallocate the resources between them. For this purpose the models of (1)-(4) type are joined for the divisions $j_{1}$ and $j_{2}$ to make a single one as follows: to determine a solution $\left\{x_{j 1 t}^{1}, x_{j 2 t}^{1}\right\}$, which allows to

\begin{tabular}{|c|c|c|c|c|c|}
\hline & & \multicolumn{4}{|c|}{$p_{i j}^{t}$} \\
\hline \multirow[t]{3}{*}{$j$} & \multirow[t]{3}{*}{ Name } & \multirow{2}{*}{\multicolumn{2}{|c|}{$\begin{array}{l}\text { Funds, conv. } \\
\text { monetary units } \\
\text { per flight }\end{array}$}} & \multicolumn{2}{|c|}{$\begin{array}{c}\text { Personnel } \\
\text { working time } \\
\text { fund expenditures } \\
\mathrm{h} / \text { flight }\end{array}$} \\
\hline & & & & & \\
\hline & & I & II & I & II \\
\hline 1 & $\begin{array}{l}\text { Terminal } \\
\text { handling division } \\
\text { (subdivision) }\end{array}$ & 170 & 150 & 8 & 6 \\
\hline 2 & $\begin{array}{l}\text { Aircraft ground } \\
\text { handling division } \\
\text { (subdivision) }\end{array}$ & 510 & 480 & 8.55 & 4.03 \\
\hline
\end{tabular}
achieve objective function maximum

$$
P_{j 1 j 2}=\sum_{t=1}^{T_{j 1}} c_{j 1 t} x_{j 1 t}+\sum_{t=1}^{T_{j 2}} c_{j 2 t} x_{j 2 t}
$$

\begin{tabular}{|c|c|c|c|}
\hline \multirow[b]{2}{*}{$j$} & \multirow[b]{2}{*}{$x_{j t}$} & \multicolumn{2}{|c|}{ Dual estimates } \\
\hline & & $\begin{array}{l}\text { Funds, conv. } \\
\text { monetary units } \\
\text { per flight }\end{array}$ & $\begin{array}{l}\text { Personnel wor- } \\
\text { king time fund } \\
\text { expenditures } \\
\text { h/flight }\end{array}$ \\
\hline \multirow[b]{3}{*}{1} & $x_{11}=166$ & \multirow{2}{*}{0.04} & \multirow{2}{*}{17.50} \\
\hline & $x_{12}=277$ & & \\
\hline & $\begin{array}{l}\text { Objective function } \\
\text { value, conv. } \\
\text { monetary units }\end{array}$ & \multicolumn{2}{|c|}{55777.78} \\
\hline \multirow{3}{*}{2} & $x_{21}=421$ & \multirow{2}{*}{0.88} & \multirow{2}{*}{0.00} \\
\hline & $x_{22}=0$ & & \\
\hline & $\begin{array}{l}\text { Objective function } \\
\text { value, conv. } \\
\text { monetary units }\end{array}$ & \multicolumn{2}{|c|}{189705.90} \\
\hline \multicolumn{2}{|c|}{ Consolidated profit } & \multicolumn{2}{|c|}{245483.68} \\
\hline
\end{tabular}

Table 3. Input data as to $i$ resource consumption per $j$ service unit

Table 4. The results of model experimental computations (1)-(4)

subject to the following sets of constraints:

$$
\begin{aligned}
& x_{j 1 t} \geq 0 ; x_{j 2 t} \geq 0 ; \\
& \sum_{t=1}^{T_{j 1}} p_{i j 1}^{t} x_{j 1 t}+\sum_{t=1}^{T_{j 2}} p_{i j 2}^{t} x_{j 2 t}<a_{i j 1}+a_{i j 2}, i=\overline{1, m} ; \\
& \bar{X}_{j 1} \geq \sum_{t=1}^{T_{j}} x_{j 1 t} \geq \underline{X}_{j 1} ; \\
& \bar{X}_{j 2} \geq \sum_{t=1}^{T_{j}} x_{j 2 t} \geq \underline{X}_{j 2} .
\end{aligned}
$$

Solving the task (5)-(9) will bring an optimal solution $\left\{x_{j 1 t}^{1}, x_{j 2 t}^{1}\right\}$, new vector of $\left\{U_{i}^{1}\right\}$ dual estimates, which corresponds now to the divisions $j_{1}$ and $j_{2}$ and also the value of the objective function $P_{j 1 j 2}^{1}$. Where by $P_{j 1 j 2}^{1}>P_{j 1}^{0}+P_{j 2}^{0}$, i.e. total profit of two divisions became higher than the result of the tasks (1)-(4) for the divisions taken separately. Indeed the in equation $P_{j 1 j 2}^{1}<P_{j 1}^{0}+P_{j 2}^{0}$ is impossible since the solution $\left\{x_{j 1 t}^{0}, x_{j 2 t}^{0}\right\}$, obtained 
from optimal solutions of tasks (1)-(4) for the divisions $j_{1}$ and $j_{2}$, is obviously feasible for the task (5)(9), and the solution $\left\{x_{j 1 t}^{1}, x_{j 2 t}^{1}\right\}$, is not only feasible but also an optimal one. Therefore the last inequation is at variance with optimality of the solution $\left\{x_{j 1 t}^{1}, x_{j 2 t}^{1}\right\}$. As a rule, the $P_{j 1 j 2}^{1}=P_{j 1}^{0}+P_{j 2}^{0}$ equality is also impossible, since the profit increment of the $j_{1}$ division being equal to $U_{i 1 j 1}^{\circ} \Delta_{i 1}$ for at least a rather small quantity of reallocated resource $\Delta_{i 1}$, exceeds the "loss" of the $j_{2}$ division being equal to $U_{i 1 j 2}^{\circ} \Delta_{i 1}$. Table 5 demonstrates the results of experimental calculation of the task solution (5)-(9) in view of the example brought above. It should be noted that the aircraft ground handling optimal plan includes the flights of the traditional airlines only; circulating assets (budgetary) constraint renders suppressive effects. The total profit of two divisions has become by 5926.92 conv. monetary units higher than under tasks (1)-(4) for the divisions taken separately.

Table 5. The results of model experimental computations (5)-(9)

\begin{tabular}{|c|c|c|c|}
\hline \multirow[b]{2}{*}{$j$} & \multirow[b]{2}{*}{$x_{j t}$} & \multicolumn{2}{|c|}{ Dual estimates } \\
\hline & & $\begin{array}{l}\text { Funds, conv. } \\
\text { monetary units } \\
\text { per flight }\end{array}$ & $\begin{array}{l}\text { Personnel working } \\
\text { time fund } \\
\text { expenditures } \\
\mathrm{h} / \text { flight }\end{array}$ \\
\hline \multirow{2}{*}{1} & $x_{11}=30$ & \multirow{4}{*}{0.88} & \multirow{4}{*}{0.00} \\
\hline & $x_{12}=0$ & & \\
\hline \multirow{2}{*}{2} & $x_{21}=548$ & & \\
\hline & $x_{22}=0$ & & \\
\hline & ssolidated profit & \multicolumn{2}{|c|}{251410.6} \\
\hline
\end{tabular}

Table 6. The results of model experimental computations (1)(4) including model (5)-(9) solution

\begin{tabular}{|c|c|c|c|}
\hline \multirow[b]{2}{*}{$j$} & \multirow[b]{2}{*}{$x_{j t}$} & \multicolumn{2}{|c|}{ Dual estimates } \\
\hline & & $\begin{array}{l}\text { Funds, conv. } \\
\text { monetary } \\
\text { units per } \\
\text { flight }\end{array}$ & $\begin{array}{c}\text { Personnel } \\
\text { working time } \\
\text { fund expenditures } \\
\mathrm{h} / \text { flight }\end{array}$ \\
\hline \multirow{3}{*}{1} & $x_{11}=294$ & \multirow{2}{*}{0.87} & \multirow{2}{*}{0.00} \\
\hline & $x_{12}=0$ & & \\
\hline & $\begin{array}{l}\text { Objective function } \\
\text { value, conv. } \\
\text { monetary units }\end{array}$ & \multicolumn{2}{|c|}{43529.41} \\
\hline \multirow{3}{*}{2} & $x_{21}=460$ & \multirow{2}{*}{0.88} & \multirow{2}{*}{0.00} \\
\hline & $x_{22}=0$ & & \\
\hline & $\begin{array}{l}\text { Objective function } \\
\text { value, conv. } \\
\text { monetary units }\end{array}$ & \multicolumn{2}{|c|}{207352.9} \\
\hline \multicolumn{2}{|c|}{ Consolidated profit } & \multicolumn{2}{|c|}{250882.31} \\
\hline
\end{tabular}

The "local task" being solved, the model (5)-(9) is "separated" again to make two models of (1)-(4) type. Moreover, the right parts of both tasks are formed subject to obtained reallocation of resources. If certain amount of resource remains underused in the event of solving task (5)-(9), when "separated", its remainder can be allocated between these two divisions in an arbitrary way. This is the end of the first stage. Resources reallocation in the example provided has allowed improving the original plan by 5398.63 conv. monetary units. The calculations have also proven that under the specified level of profit, costs and productivity, it will be more effective for an AGHC to provide services to the airlines with the traditional business model (Table 6).

Should one consider an AGHC with more than 2 divisions, again two divisions have to be taken for which the difference of dual estimates by certain resource is maximal, and the model of the second "local task" is developed in the same way, etc. Should the dual estimates for each type of resource for all the units be equal between each other, the process comes to its end.

\section{Conclusions}

The article describes the possibility to use dual estimates for solving practical tasks of optimal operations of the AGHC with limited resources.

The mathematical model (1)-(4) is formulated in a standard form. While the other models (Clausen 2011; Vicente 2010; Trabelsi et al. 2013) help to reduce the turnaround time and to optimize the involved staff scheduling, the model (1)-(4) can be useful for shorttime and forward planning of AGHC's internal resources and their reallocation between subdivisions with the purpose of company's functioning efficiency improving in general. When being implemented for a specific airport one may need to modify it taking into account additional constraint system requirements (e.g. when a division has the possibility to render several types of services or doesn't have it) and also when selecting a performance criterion.

The numerical results for the solution of the task under the question which were obtained with the LINDO software package, proved validity of the specified theoretical preconditions and allowed to improve the work schedule of the experimental AGHC in accordance with the efficiency criterion given.

\section{References}

Airport Research Center. 2009. Study on the Impact of Directive 96/67/ec on Ground Handling Services 1996-2007 [online], [cited 06 August 2014]. Available from Internet: http://ec.europa.eu/transport/modes/air/studies/doc/airports/2009_02_ground_handling.pdf

Albers, S.; Koch, B.; Ruff, C. 2005. Strategic alliances between airlines and airports - theoretical assessment and practical evidence, Journal of Air Transport Management 11: 48-58. http://dx.doi.org/10.1016/j.jairtraman.2004.08.001

Clausen, T. 2011. Airport Ground Staff Scheduling: PhD thesis [online], [cited 06 August 2014]. Available from Internet: 
http://orbit.dtu.dk/fedora/objects/orbit:86371/datastreams/ file_5682298/content

Gališanskis, A. 2004. Aspects of quality evaluation in aviation maintenance, Aviation 8(3): 18-26.

Gdalevich, S. 1974. Questions of Applied Use of Dual Estimates: Preprint. Moscow: The Central economic-mathematical Institute Academy of Sciences of the USSR.

IATA. 2014. Airport Handling Manual: AHM 175 - Fuelling with Passengers on-Board or During Embarkation or Disembarkation.

Kantorovich, L. V. 1959. Economic Calculation the Best Use of Resources. Moscow: Academy of Sciences of the USSR.

Lasdon, L. S. 2002. Optimization Theory for Large Systems. Mineola, New York: Dover Publications, Inc.

Trabelsi, S. F.; Cosenza C. A. N.; Cruz L. G. Z., et al. 2013. An operational approach for ground handling management at airports with imperfect information, in ICIEOM 2013, 19th International Conference on Industrial Engineering and Operations Management [online], [cited 06 August 2014]. Available from Internet: http://hal-enac.archives-ouvertes.fr/ docs/00/92/50/45/PDF/Fitouri-Trabelsi_ICIEOM2013.pdf

Vicente, S. S. 2010. Ground Handling Simulation with CAST: Master thesis [online], [cited 06 August 2014]. Available from Internet: http://www.fzt.haw-hamburg.de/pers/ Scholz/arbeiten/TextSanz.pdf

Yudin, D. B.; Holstein, E. G. 2012. Linear Programming. Theory, Methods and Applications. Moscow: Krasand.

Yun, G. N.; Marintseva, K. V. 2013.The step-by-step approach to the development of air transportation system management, Bulletin of Engineering Academy of Ukraine (3/4): 286-290. 